\title{
Design of farming systems for low input conditions: principles and implications based on scenario studies with feed allocation in livestock production
}

\author{
J.B. SCHIERE*, J. DE WIT, F.A. STEENSTRA AND H. VAN KEULEN \\ Animal Production Systems Group, Wageningen Institute of Animal Sciences, \\ Wageningen Agricultural University, P.O. Box 338, NL-6700 AH Wageningen, The Netherlands \\ * Corresponding author (fax: +31-317-485006; e-mail: hans.schiere@ dps.vh.wau.nl)
}

Received 27 January 1998; accepted 18 May 1999

\begin{abstract}
This study addresses the issue of designing farming systems for low input conditions. By focusing on the problem of feed (=resource) allocation in livestock systems it provides clues for the design of alternative agricultural systems and systems in general. Linear programming (LP) is used to examine system behaviour under conditions of varying feed resource qualities, for individual animal production levels that range from 0.75 to 3.00 times maintenance. Milk yield, animal numbers and amounts of feed offered or refused are measures of system performance in two hypothetical Cases representative for actual farming systems. Case 1 considers available feed as one aggregated resource, with an average nutritive value ranging from that of straw to that of high quality forage. It establishes the individual animal output level that is required to achieve maximum total system output from a given feed resource. In Case 2, animals of different production levels are allowed to select between two feed resources that, through proper definition of the their proportions on offer, on average represent the same feed quality scale as in Case 1. The possibility of selection, however, allows the nutritive value of the actual intake to differ from the average nutritive value of feed offered. Better feed and higher (potential) individual animal output tend to increase total system output in terms of milk, by reducing the number of animals. Nevertheless, the term 'damning objective' is introduced to express that high targets for subsystem output reduces total system output if subsystem requirements exceed resource availability. Moreover, heterogeneity of (feed) resources can increase system output by using more production units with lower individual output. The results are tested against farmers' practice and situations reported in literature. Implications for the design of sustainable systems and further research are discussed.
\end{abstract}

Keywords: external inputs, livestock feeds, best technical means, damning objective, farming systems design, genotype - environment interaction, linear programming

\section{Introduction}

The shape and behaviour of systems in general, and therefore also of farming systems, interact with their boundary conditions (Prigogine \& Stengers, 1985; Cohen \& 
Stewart, 1994; Schiere, 1995). Changes in boundary conditions force crop and/or livestock systems to reassess methods and objectives of production. Taking the change in boundary conditions as cause and result of innovations, it is convenient to classify farming systems on the basis of their access to land, labour and capital. That results in a (schematic) distinction between systems from Low External Input Agriculture (LEIA) and High External Input Agriculture (HEIA) (Schiere, 1995). Farming systems in LEIA need redesigning due to exhaustion of local resources and the need to feed and clothe a growing population (Van der Pol, 1992). In contrast, HEIA systems need to be redesigned also, since they apply high levels of external input with inherent and increasingly apparent problems of waste disposal (Durning \& Brough, 1991; De Haan et al., 1997). This paper uses simplified scenario studies with linear programming to explore the possibilities of designing new systems, exemplified for the Case of feed allocation in ruminant production systems. It identifies the output of a subsystem (= individual animal) that maximises animal output from a given quantity of feed resources. By matching these feed resources with different types of animals it explores the mutual adjustment of animals and feeds for achieving maximum system output. This reflects the LEIA strategy where the objectives of the system and of the subsystems tend to be adjusted to the access to inputs, whereas HEIA tends to adjust input use to the output target of the system (Schiere \& De Wit, 1993). To mimic LEIA conditions, this paper assumes that the animals depend entirely on feed resources available from grazing and cropping within the farming system. Such feed biomass can consist of a mix of poor quality grasses and fibrous crop residues with varying levels of high quality fodders and offals from grain and/or oilseed processing. Purchase of feed is assumed to be impossible in LEIA, but the use of increasing quantities of good quality feed illustrates what happens when - as in HEIA - better feed is available from outside. Two Cases are presented: (i) adjustment of animal characteristics to the feed, (ii) mutual adjustment of feed quality and animal characteristics. System output is expressed in terms of milk yield, number of animals and amount of feed refused. The study aims at understanding issues of (feed) resource allocation only, and economic assessment is not attempted. The focus on feed allocation provides analogy with other sectors of society, because feed represents a major part of the energy flux in livestock systems, and energy fluxes are a major determinant of system behaviour at all levels of system hierarchy (Odum, 1971; Prigogine \& Stengers, 1984; Schiere, 1995). It is hypothesised, therefore, that the results of this study can be extrapolated to other systems as illustrated in the discussion.

\section{Materials and methods}

\section{Models and software}

Various specialised software packages are available for optimising feed allocation and simulation of livestock systems in general (Zemmelink et al., 1992; Udo \& Brouwer, 1993). Our scenario studies apply linear programming (LP), because it is 
specifically designed to deal with resource allocation and it provides a platform for interdisciplinary discussion (cf. Van de Ven, 1996). Most of the problems commonly attributed to LP such as issues of linearity or supposed lack of time dimensions can be overcome by legitimate mathematical methods. (Romero \& Rehman, 1989; Van Niejenhuis \& Renkema, 1989). The 'problem' that LP gives one rather than a range of solutions can be overcome by running the model several times for different conditions (see for example Morrison et al., 1986; Kingwell \& Pannell, 1987). Multiple runs have the added advantage that they allow the use of a small and more transparent matrix by reducing the number of variables. The multiple runs and the recording of outputs were automated with a set of macros in LOTUS 1-2-3, version 2.0.

\section{System output and animal units}

System output was expressed as milk yield (4\% fat-corrected milk), number of cows, and amount of feed consumed or refused. The calf crop, milk consumed by the calf, other herd components such as bulls or growing animals, meat, draught or dung production were not considered, an issue that will be elaborated in the discussion. Animal subsystem output was expressed on the basis of animal units for maintenance $\left(\mathrm{AUM}_{\mathrm{TDN}}\right)$, here called ' $\mathrm{M}$ ', (Table 1). A production level of $0.75 \mathrm{M}$ is included because survival, even at negative weight gain, is an essential form of animal production in farming systems with fluctuating feed supplies. Even in developed countries the value of survival is recognised, as witnessed by terms such as 'survival feeding' or 'wintering rations' (Morrison, 1961; Barker \& Stoate, 1969; Farrington et al., 1989).

Table 1. Definition of animal units (AUM) based on level of production, expressed as multiples of maintenance for requirements for protein $\left(\mathrm{AUM}_{\mathrm{CP}}\right)$ and energy $\left(\mathrm{AUM}_{\mathrm{TDN}}\right)$.

\begin{tabular}{|c|c|c|c|c|c|c|c|c|c|c|c|}
\hline AUM & & 0.75 & 1.00 & 1.25 & 1.50 & 1.75 & 2.00 & 2.25 & 2.50 & 2.75 & 3.00 \\
\hline Milk yield ${ }^{1}$ & $\left(1\right.$ animal $\left.^{-1} \mathrm{~d}^{-1}\right)$ & 0.00 & 0.01 & 2.19 & 4.39 & 6.58 & 8.77 & 10.96 & 13.16 & 15.35 & 17.54 \\
\hline CP-Maint. ${ }^{3}$ & 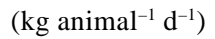 & 0.29 & 0.29 & 0.29 & 0.29 & 0.29 & 0.29 & 0.29 & 0.29 & 0.29 & 0.29 \\
\hline CP-Milk & 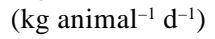 & -0.20 & 0.00 & 0.20 & 0.40 & 0.60 & 0.79 & 0.99 & 1.18 & 1.38 & 1.58 \\
\hline CP-Total ${ }^{2}$ & $\left(\mathrm{~kg}\right.$ animal $\left.{ }^{-1} \mathrm{~d}^{-1}\right)$ & 0.09 & 0.29 & 0.49 & 0.68 & 0.88 & 1.08 & 1.27 & 1.47 & 1.67 & 1.87 \\
\hline TDN-Maint. ${ }^{3}$ & $\left(\mathrm{~kg}\right.$ animal $\left.{ }^{-1} \mathrm{~d}^{-1}\right)$ & 2.82 & 2.82 & 2.82 & 2.82 & 2.82 & 2.82 & 2.82 & 2.82 & 2.82 & 2.82 \\
\hline TDN-Milk & $\left(\mathrm{kg}\right.$ animal $\left.{ }^{-1} \mathrm{~d}^{-1}\right)$ & -0.71 & 0.00 & 0.71 & 1.41 & 2.12 & 2.82 & 3.53 & 4.24 & 4.94 & 5.65 \\
\hline TDN-Total ${ }^{2}$ & $\left(\mathrm{~kg}\right.$ animal $\left.{ }^{-1} \mathrm{~d}^{-1}\right)$ & 2.12 & 2.82 & 3.53 & 4.24 & 4.94 & 5.65 & 6.35 & 7.06 & 7.77 & 8.47 \\
\hline $\mathrm{AUM}_{\mathrm{CP}}$ & & 0.32 & 1.00 & 1.69 & 2.37 & 3.06 & 3.75 & 4.44 & 5.12 & 5.81 & 6.50 \\
\hline $\operatorname{AUM}_{\mathrm{TDN}}(=\mathrm{M})$ & & 0.75 & 1.00 & 1.25 & 1.50 & 1.75 & 2.00 & 2.25 & 2.50 & 2.75 & 3.00 \\
\hline $\mathrm{F}_{\mathrm{p}}$ & & 0.88 & 1.00 & 1.12 & 1.25 & 1.38 & 1.50 & 1.62 & 1.75 & 1.88 & 2.00 \\
\hline
\end{tabular}

1 This table gives a milk yield of 0.0001 and 0.01 liter animal ${ }^{-1} \mathrm{day}^{-1}$ for AUM 0.75 and 1.00 liter animal $^{-1} \mathrm{day}^{-1}$ in the objective function of the LP matrix as a trick to positively value survival, and allowing easy recognition of these outputs as being hypothetical; theoretical milk output should be resp. -2.19 and 0.0 lts.animal $^{-1}$.day ${ }^{-1}$ (see text).

2 Requirements are based on Anonymous (1988; Table 6.3); 3.55 g CP. $\mathrm{kg}^{-0.75}$ and 34.9 g TDN.kg ${ }^{-0.75}$ for maintenance, and $90 \mathrm{~g} \mathrm{CP}$ with $322 \mathrm{~g}$ TDN per litre of milk.

3 CP-maint., CP-milk, CP-total etc. refer to the requirements for nutrient expressed as CP and TDN for maintenance, for milk and for the total respectively. 


\section{The cases}

The scenario studies were applied to two imaginary cases that reflect actual field conditions. The important difference between Cases 1 and 2 is that feed is a homogenous inseparable mix of high and low quality components in Case 1 where selection between the feed components is not possible, while in Case 2 it is a separable mix of the two feeds, permitting selection between feed components by the farmer and/or the animal. The range in average nutritive value of the feed offered is the same in both cases, but the possibility of selection between feeds in Case 2 may result in differences in the nutritive value of the actual intake. Nutritive values, expressed as TDN40/CP4 indicate that the content of total digestible nutrients (TDN) is 40 and that of crude protein $(\mathrm{CP}) 4$, both expressed as percentage of the dry matter. The effects of varying quality of feed and type of animal are predicted for:

\section{CASE 1:}

1A: a fixed quantity of two feeds comprising an inseparable mix of, for example, straw (TDN40/CP4) and high quality fodder (TDN70/CP16). Their ratio in the mix varies from 100/0 to $0 / 100$ with a corresponding improvement in nutritive value. The feed is offered to animals ranging in production level from $0.75 \mathrm{M}$ to $3.00 \mathrm{M}$ in increments of $0.25 \mathrm{M}$ with the associated increase in intake. This is done by introducing $\mathrm{F}_{\mathrm{p}}$, a factor that corrects dry matter intake (DMI) as a function of the level of milk production expressed per multiple of maintenance (Anonymous, 1988; B.J. Tolkamp, pers. comm., 1994). The value $F_{p}$ starts at 1 for animals at $1 \mathrm{M}$ and it increases linearly to 2 for animals at $3 \mathrm{M}$ (Table 1).

1B: as $1 \mathrm{~A}$ but with $\mathrm{F}_{\mathrm{p}}$ constant at 1 ;

$1 \mathrm{C}$ : as $1 \mathrm{~A}$, with the feed value ranging from TDN55/CP10 to TDN65/CP14 in smaller increments.

CASE 2:

2A: as $1 \mathrm{~A}$ but the feeds are segregated to allow selection of feed;

2B: as 2A, but the basal feed is of better quality, e.g., straw is replaced by medium quality grass TDN55/CP10.

\section{The matrix}

Only one small matrix is required (Table 2) because different values for variables and coefficients are used in multiple runs. Thus, the value of the coefficients differs per case as explained below:

- objective values

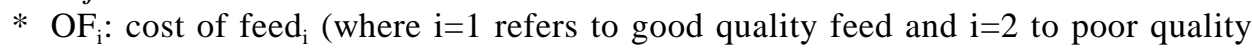
feed). It is here valued at ' 0 ' in all cases. The use of feeds is restricted only by their availability and nutritive value (see constraint $\mathrm{CF}_{\mathrm{i}}$ ).

* $\mathrm{OS}_{\mathrm{i}}$ : cost of feed not ingested $\left(\mathrm{VS}_{\mathrm{i}}\right)$, is also ' 0 ', being a so-called store variable, as explained under 'variables'. 
Table 2. The LP matrix used for all Cases (see text for explanation of variable and objective codes)

\begin{tabular}{|c|c|c|c|c|c|c|c|c|}
\hline & $\begin{array}{l}\text { Variable code } \\
\text { Objective code }\end{array}$ & $\begin{array}{l}\mathrm{VF}_{1} \\
\mathrm{OF}_{1}\end{array}$ & $\begin{array}{l}\mathrm{VS}_{1} \\
\mathrm{OS}_{1}\end{array}$ & $\begin{array}{l}\mathrm{VF}_{2} \\
\mathrm{OF}_{2}\end{array}$ & $\begin{array}{l}\mathrm{VS}_{2} \\
\mathrm{OS}_{2}\end{array}$ & $\begin{array}{l}\mathrm{VA}_{1} \\
\mathrm{OA}_{1}\end{array}$ & & RHS \\
\hline & Objective value & 0 & 0 & 0 & 0 & 2.19 & & MAX \\
\hline $\mathrm{CF}_{1}$ & DM available (good) & 1.00 & 1.00 & & & & $=$ & 16.00 \\
\hline $\mathrm{CF}_{2}$ & DM available (poor) & & & 1.00 & 1.00 & & $=$ & 4.00 \\
\hline $\mathrm{Ctdn}_{1}$ & TDN min & 0.70 & & 0.55 & & -3.53 & $>$ & 0.00 \\
\hline $\mathrm{Ccp}_{1}$ & $\mathrm{CP} \min$ & 0.16 & & 0.10 & & -0.49 & $>$ & 0.00 \\
\hline $\mathrm{Cmax}_{1}$ & DMI max (good) & 1.00 & & 1.00 & & -8.77 & $<$ & 0.00 \\
\hline $\mathrm{Cmax}_{2}$ & DMI max (poor) & & & 1.00 & & -6.89 & $<$ & 0.00 \\
\hline
\end{tabular}

Note: the coefficients in this Case belong to Case $2 \mathrm{~b}$, with a milk production of $1.25 * \mathrm{M}$, i.e. 2.191 ani$\mathrm{mal}^{-1} \mathrm{~d}^{-1}$.

* $\mathrm{OA}_{\mathrm{i}}$ : individual animal output expressed as milk production $\left(1\right.$ animal $\left.{ }^{-1} \cdot \mathrm{d}^{-1}\right)$, as specified in Table 1 . The objective values are 0.001 for $0.75 \mathrm{M}, 0.01$ for $1 \mathrm{M}, 4.4$ for $1.5 \mathrm{M}$, subsequently increasing with constant increments to 17.51 at $3 \mathrm{M}$ (Table 1) . The use of 0.0001 and 0.01 in the objective row for animals at 0.75 and $1 \mathrm{M}$ ensures that the model picks up animals at sub-maintenance and maintenance, with values that can easily be recognised, but that do not inflate the total objective value.

\section{- variables}

* the sum of $\mathrm{VS}_{\mathrm{i}}+\mathrm{VF}_{\mathrm{i}}$ is the total feed offered, $\mathrm{VF}_{\mathrm{i}}$ is feed consumed and $\mathrm{VS}_{\mathrm{i}}$ is a 'store' for refused feed. $\mathrm{VS}_{\mathrm{i}}$ allows animals to refuse feed, e.g. when the DMI of a feed is too low to satisfy nutrient requirements. $\mathrm{VS}_{\mathrm{i}}$ can be made obsolete by setting $\mathrm{VF}_{\mathrm{i}}$ to the maximum amount of feed to be fed: its slack value then represents $\mathrm{VS}_{\mathrm{i}}$. That would, however, complicate alternative uses of $\mathrm{VS}_{\mathrm{i}}$, e.g. transfer to other seasons or use as bedding, mulch or thatching in expanded calculations.

* $\mathrm{VA}_{\mathrm{i}}$ is the number of animals at a given level of production finally selected by the model for the given feed supply in a model run.

\section{- constraints}

* $\mathrm{CF}_{1}$ is the availability of good fodder, estimated at $7200 \mathrm{~kg} \mathrm{DM} \mathrm{ha}^{-1} \mathrm{yr}^{-1}(=20 \mathrm{~kg}$ $\left.\mathrm{d}^{-1}\right) . \mathrm{CF}_{2}$ is the availability of poor feed such as straw. The maximum availability of good fodder as well as the maximum availability of straw is $7200 \mathrm{~kg} \mathrm{ha}^{-1}$, i.e. $20 \mathrm{~kg} \mathrm{~d}^{-1}$ based on two grain crops per year, each yielding $3000 \mathrm{~kg}$ grain ha ${ }^{-1}$. The yield of brans and ratoon is disregarded. The yields of poor and good quality feed were assumed to be equal to avoid confounding effects of quality and quantity. For the same reason, the organic matter content of all feeds was assumed to be equal, a simplification that does not affect the essence of the results.

* $\mathrm{Cmax}_{\mathrm{i}}$ is the maximum DMI values of the feeds, estimated by:

$\mathrm{OMI}=-42.8+2.3039 * \mathrm{OMD}-0.0175 * \mathrm{OMD}^{2}-1.8872 * \mathrm{~N}^{2}+0.2242 * \mathrm{~N}^{*} \mathrm{OMD}$

(Ketelaars \& Tolkamp, 1992)

$\mathrm{DMI}=\mathrm{OMI} * \mathrm{~F}_{\mathrm{a}} * \mathrm{OM}^{-1} * \mathrm{~F}_{\mathrm{p}}$ 


\section{J.B. SCHIERE, J. DE WIT, F.A. STEENSTRA AND H. VAN KEULEN}

where OMI is organic matter intake $\left(\mathrm{g} \mathrm{kg}^{-0.75} \mathrm{~d}^{-1}\right)$, OMD is organic matter digestibility; $\mathrm{N}$ is nitrogen content, expressed as \% of organic matter; DMI is dry matter intake $\left(\mathrm{g} \mathrm{kg}^{-0.75} \mathrm{~d}^{-1}\right) ; \mathrm{F}_{\mathrm{a}}$ is a factor that converts values obtained on sheep to values that are valid for cows (B.J. Tolkamp, pers.comm., 1994); and $\mathrm{F}_{\mathrm{p}}$ is a correction factor for DMI according to animal production level.

* $\mathrm{Ctdn}_{\mathrm{i}}$ and $\mathrm{Ccp}_{\mathrm{i}}$ represent the rows with the nutrient requirements of the animals (Anonymous, 1988), and the nutritive values of the feeds used.

\section{Results}

System performance is expressed in terms of milk production, number of animals and feed refused. The results of the calculations are summarised in Figures 1 and 2 where, for example, graph $1 \mathrm{Ap}$ refers to milk production for Case 1A, graph $1 \mathrm{Aa}$ refers to the number of animals for Case $1 \mathrm{~A}$ and graph $2 \mathrm{Af}$ shows the amount of poor feed consumed for Case 2A. As the general features of the graphs are similar, the text refers to lines such as MM', F'F', etc. as in figure 1Ap with their analogous lines in the other graphs. The first observation is that a better quality feed resource
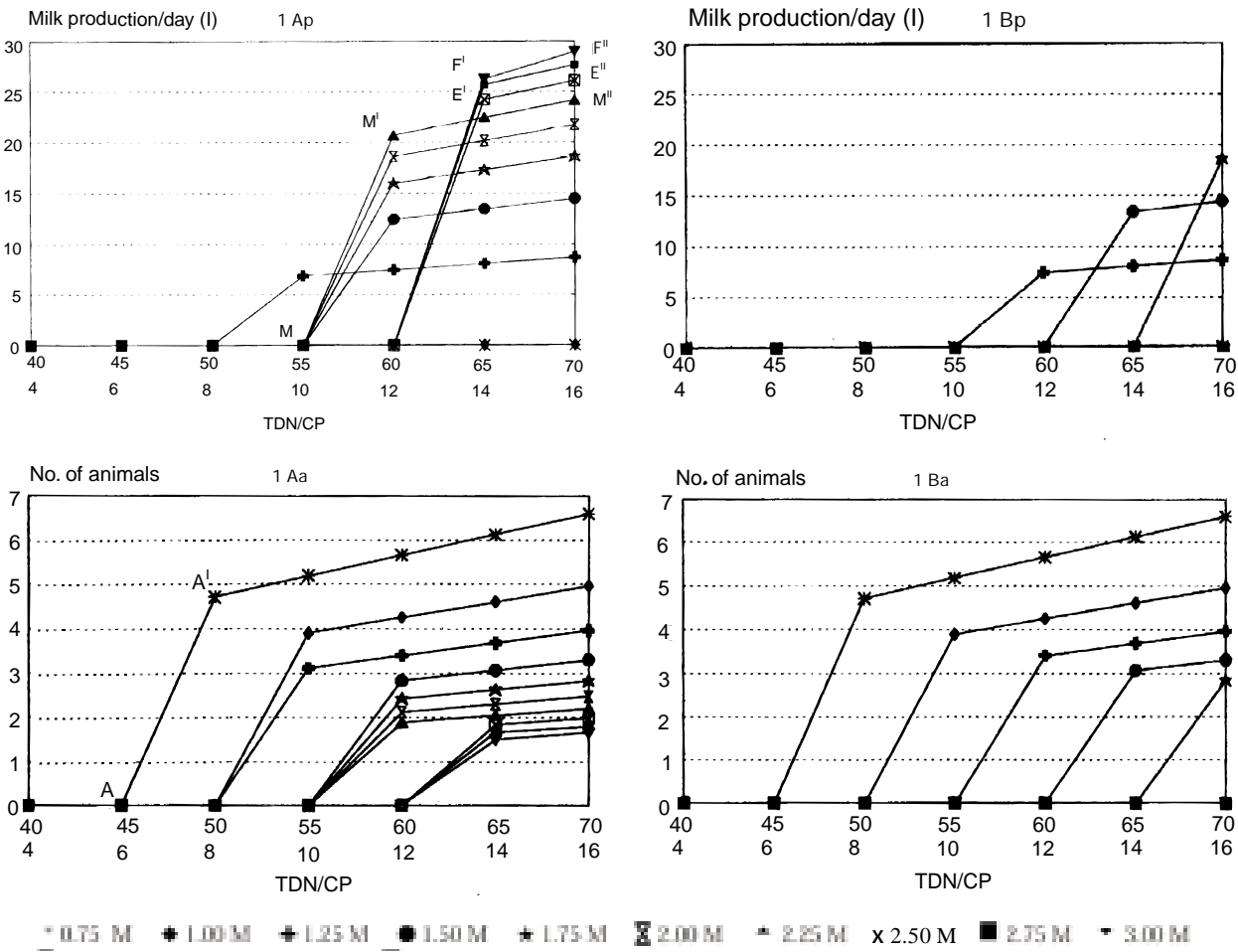

$8200 \mathrm{Mt}+225 \mathrm{M} \times 2.50 \mathrm{M}$

Figure 1. The effect of changing feed quality and individual animal output on total milk production and number of animals, with (1A) and without (1B) adjusting feed intake for production level of the animal through $\mathrm{F}_{\mathrm{p}}$. 

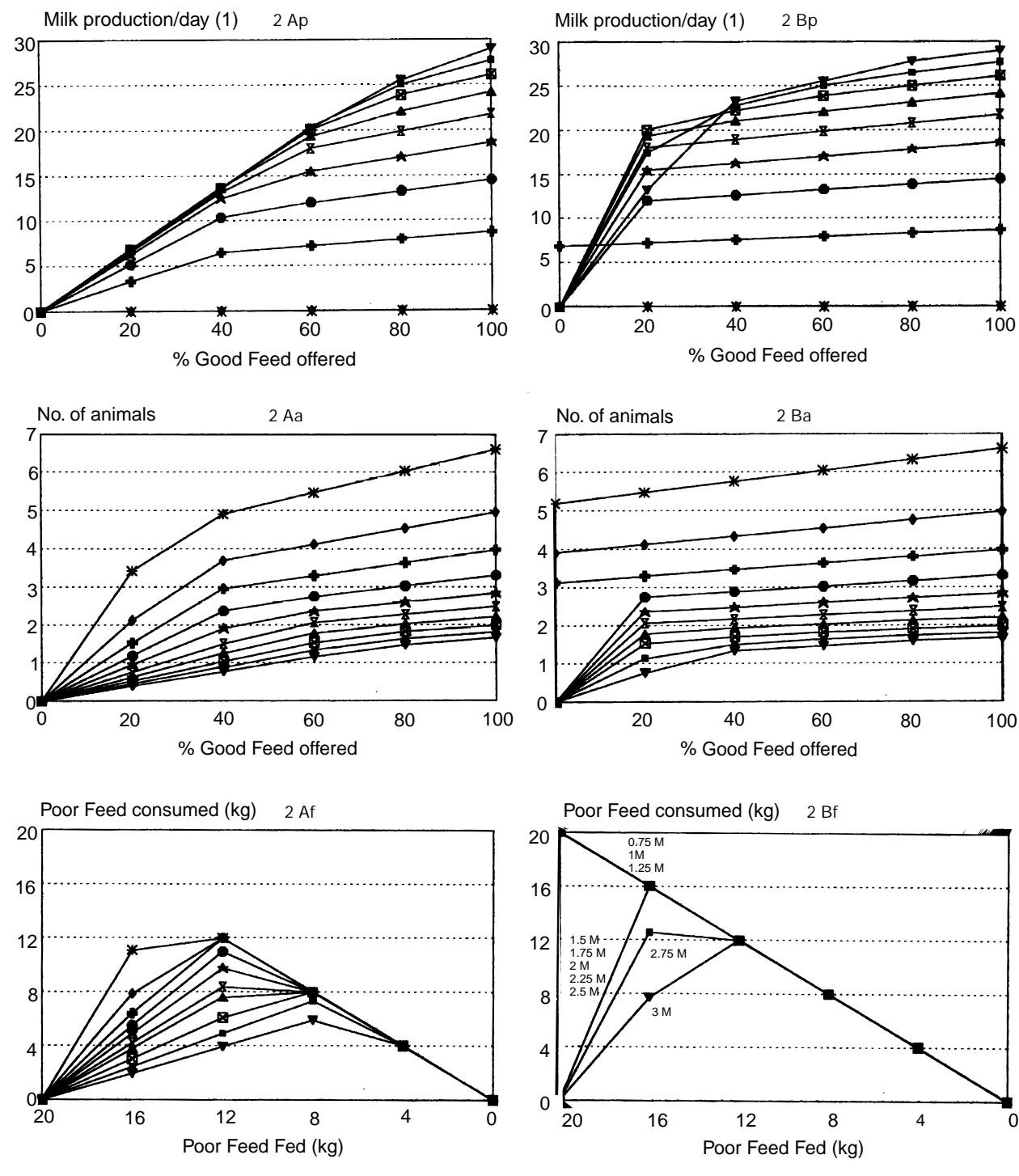

$-0.75 \mathrm{M}+1.00 \mathrm{M}+125 \mathrm{M}$

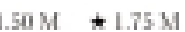

$8200 \mathrm{ML}+225 \mathrm{M}+2.50 \mathrm{M}=275 \mathrm{M}+3.00 \mathrm{M}$

Figure 2. The effect of a changing mix of feed, in which selection is possible, from feeds with respectively TDN40/CP4 (Figure 2A), or TDN50/CP10 (Figure 2B) to TDN70/CP16, at different levels of individual animal output on total milk output, number of animals, and quantity of feed refused.

always leads to higher total system output, either expressed as milk or as total number of animals, if output/animal is kept constant. This effect shows up in all situations illustrated in Figures 1 and 2 by proceeding from left to right along the $\mathrm{X}$-axis. Figure 3 has been included because it shows the general effects - here for milk pro- 

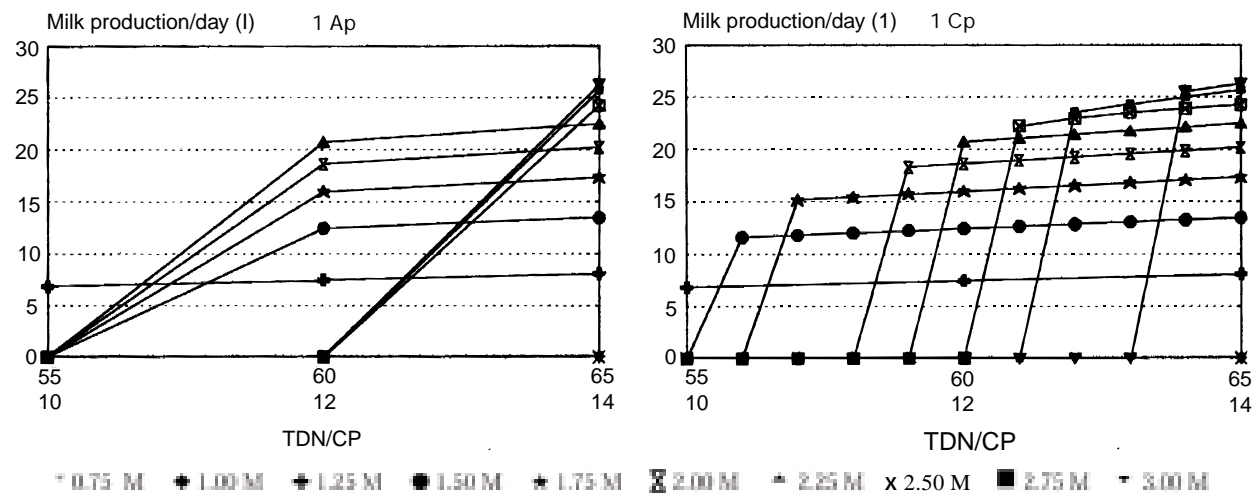

Figure 3. The effect of smaller increments on the shape of the output figures, calculated for ten (case Ic) rather than two (case Ib) increments on the scale from TDN55/CP10 to TDN65/CP14.

duction - with higher resolution, i.e. with smaller increments of increasing feed quality than in Figures 1 and 2. This also avoids the suggestion, such as in Figure 1, that output curves $3 \mathrm{M}, 2.75 \mathrm{M}$ and $2.5 \mathrm{M}$ converge to zero at one point of feed quality. The second observation is that increased feed quality results in higher total system output by using fewer animals with a higher output per individual animal (e.g. $F^{\prime} F$ " is preferred over E' E" in Figure 1Ap). The system would only use more animals (line A'A" in figure 1Aa) when the production per individual animal is not allowed to increase. The third observation is that animals (subsystems) with high individual outputs only result in higher total system output when the quality of the available feed is good enough. For example, total system output in terms of milk at TDN60/CP12 is lower for $2.5 \mathrm{M}$ than for $2.25 \mathrm{M}$ animals (Figure 1Ap). In other words, conditions of limited feed resource quality may force the farmer to accept lower individual subsystem milk output to achieve higher total system milk output. This may seem artificial due to the simplification that a $2.5 \mathrm{M}$ cow cannot function as a $2.25 \mathrm{M}$ cow, but the point is that rigid and high subsystem production targets can reduce total system output. We propose to call this, by lack of a better description, the principle of the 'damning objective'. The fourth observation is that segregation of feed resources, or the possibility of selective consumption (Zemmelink, 1986), can increase total system milk output by allowing part of its poor quality (feed) resources to be left unused (Case 1A versus Case 2A). The amount of feed refused is shown in Figure 2Af; refusals being higher at higher levels of individual animal output. The fifth observation follows from the fourth: excessive subsystem production targets can cause resource wastage, in this case of feed, if no alternative use is found for such a resource (Staniforth, 1982). Thus, segregation of (feed) resources allows higher system output, provided that the subsystem output is adjusted to the resource quality (compare Figs. 1Ap and 2Ap). To avoid wastage and to achieve higher total output, the system should also include subsystems geared to utilise the lower quality resources. Comparison of Figures $1 \mathrm{Ap}$ and $2 \mathrm{Ap}$ further shows that the effect of the damning objective is less when selection is allowed (1Ap), an observation that 
favours segregation of poor and good quality resources in LEIA that cannot purchase resources from outside. In contrast, HEIA can import feed, making it possible that milk output of an individual cow (a subsystem) increases when good quality feed resources are used as a supplement.

\section{Discussion}

Our studies explore options for the design of (animal) production systems that maximise system milk output under conditions of restricted access to variable resources. Feed allocation is a "model" for resource allocation in general, and the results are therefore relevant for system behaviour in general. Restricted access to resources can be due to low purchasing power caused by low produce prices in LEIA, but HEIA is also under pressure to reduce input use due to problems associated with nutrient emissions (Durning \& Brough, 1991; De Haan et al., 1997). Therefore, LEIA strategies provide clues for HEIA systems where access to inputs and disposal of waste were not considered to be a problem until recently.

Our cases deal with imaginary animals and feeds, but they represent actual situations, e.g., feeds at the left side of the $\mathrm{X}$-axis in Figure 1 represent poor quality roughages such as straws, but they change towards very high quality fodder while proceeding to the right. Case 2 represents a situation with a mixture of two feeds, e.g., straws and good fodder with the ratio of poor to good feed decreasing when going to the right on the $\mathrm{X}$-axis in Figure 2. Feed quantity is kept constant and more such simplifications have been used but none appears to affect the general conclusions (Schiere, 1995). Testing results from scenario studies through experimentation is difficult since scenario studies intend to understand and explore options beyond practical experimentation (Stoorvogel et al., 1995; Veldkamp \& Fresco, 1996). Moreover, discrepancies between model and practice can originate from imperfections in the models as well as from suboptimal practice (Sol et al., 1984; Morrison et al., 1986; Arthur, 1990). Outcomes of scenario studies should be tested nevertheless, here done by using observations from practice and by seeking analogies with concepts from other disciplines.

Increased system milk output on better feed by using fewer animals of higher individual output typically reflects the basis of HEIA strategy that solves shortage of resource quality by purchasing (feed) resources from outside the system. They discard on-farm resources such as straws, a practice that can ultimately lead to problems of waste disposal (Kelley, 1992). Also, farmers' preference for fertiliser rather than dung has caused nutrients from manures to be wasted in HEIA systems (Van Der Meer et al. , 1987; De Boer et al., 1997). Moreover, cows with high individual milk yields need more than good quality feed resources alone, such as housing and veterinary care. This entails costs that are often ignored and that thus lead to overestimate resource use efficiency in HEIA. This need for additional non-feed resources for high milk output balances to some extent the simplification that requirements for calves are not taken into account. The need for additional resources also reflects the fact that only a proper balance of all production factors increases total system out- 
put. It is the basis of the notion of Best Technical Means (BTM) (De Wit, 1992) which implies that all production factors should be as close as possible to their optimum to attain maximum efficiency of a given production factor. This argument of increased output - and implicitly efficiency - at higher individual yields also runs the other way, however, since there is no point in keeping high potential animals if feed resources and housing are not adequate. The analogy with systems other than animal production is compelling. For example, tropical agricultural development abounds with failures of crop and livestock where introduction of pure-breds cows and/or high yielding crop varieties can be counterproductive, or in our terms: a damning objective (Anonymous, 1987; Durning \& Brough, 1991). While hypothesising that this is a generalised form of genotype-environment interaction, it should be possible to estimate the type and number of (sub)systems that can be kept under a given resource supply, i.e. allowing the design of the 'BTM' farming system ideotype (Donald, 1962; Aarts et al., 1992) with subsystems for highest total system output and minimum waste disposal problems. The damning objective was defined as a rigid output target that exceeds the potentials set by the resources of the (farm) system. It either reduces total system output, or it leaves the system with three options: to adjust the subsystem target, to adjust resource supply to the target $e$.g., by importing (feed) resources, or to use reserves from within. Either option affects sustainability of the system by using resources from elsewhere or by using resources that might be used in the future. A damning objective in HEIA may also prevent the use of low quality (feed) resources, thus resulting in increased wastage of resources through burning of straw or disposal of animal excreta. Recycling of these on-farm resources is practised in LEIA. that values - for example - the excreta for the crops and the straw as a maintenance feed for the animals. (Ifar, 1996; Zemmelink, 1986). Even former HEIA systems now accept that manure surpluses need to be reduced through recycling (Van Der Meer et al., 1987; Biewenga et al., 1992; Rerat \& Kaushik, 1995).

Adjustment of individual animal output to lower quality feed resources has received less attention than breeding and feeding for higher individual animal output. For example, the work by Frisch \& Vercoe (1978), Hayman (1974) and Alexander et al. (1984) on genotype environment interactions hardly mention breeding for poor quality feed utilisation. Cases of animal breeding to adjust to feed supply are available, however, in the stratification of sheep breeds for the Scottish highlands. Fraser (1949) implicitly refers to the damming objective as he observes for those typically low input conditions: 'it is quite impossible to produce a first-quality lamb off a barren hill-side. All that the land's fertility will support is the slow growth and slow reproduction rate of hill breeds of sheep [...].

Segregation of feeds such as straws and concentrates is called selective consumption (Zemmelink, 1980; Wahed et al., 1990). The need for selective consumption depends on the desired level of animal production and on feed availability. Mixing of bad with good feeds, e.g. by chopping or mixing to discourage selective consumption can be useful in systems that prefer to keep more animals at lower individual milk output, combined with higher preference for dung, draught, and saving account functions (Zemmelink et al., 1992; De Wit et al. 1993). It can also be used where an- 
imals have to survive a lean season to take advantage of 'cheap' liveweight gains in the lush season (Allden, 1970; O'Donovan, 1984; Kamalzadeh, 1996). The mixing of different good feeds in HEIA is clearly a different case since it tends to purchase feeds from elsewhere for optimum rumen functioning and animal output. The "wasting" of poor quality resources to achieve higher total system output is an important analogy with industrial systems that separate the "good" from the "bad", prior to using recycled waste as a resource.

Testing of the results from these scenario studies can also be done by using analogies from general system behaviour, thus leading to a discussion of the implications of these studies. The first point, i.e., that target setting for subsystem yields should consider resource availability for the total system, tallies with the concept of the "communal ideotype" as defined for wheat breeding (Donald, 1981). He shows that the ideal wheat plant type needs to be designed for maximum plot output, not for maximum plant yield. This is well known to farmers who accept low plant yields by dense spacing in order to obtain higher plot yields. For animal production this is recognised by Jones \& Sandland (1974) and Breman \& de Wit (1983) and for whole farm planning for example by Kidane (1984) and Patil et al. (1993).

The second point relates to a generalisation of the genotype - environment interaction, i.e., the fact that the access to resources (the niche) determines the choice of (animal) subsystem. (Schiere et al., 1999) This implies that BTM depends on access to resources, and the sustainable cow, plant or farming system does therefore not exist as it needs to match the resources. Analogy with examples from other disciplines than agriculture is further apparent in the fact that restricted access to a variety of resources reflects the essence of the two laws of thermodynamics. They state that energy and resources cannot be created nor lost, but that they tend to be transformed into a direction where they become less available In simple terms, all processes taken together tend towards formation of waste. The implication of these laws is masked in HEIA systems by a cornucopian paradigm that tends to ignore resource depletion and waste production (Daly et al., 1990; Schiere et al., 1999). Our scenario studies show that both too high (the damning objective) and too low subsystem yield targets lead to waste and reduced total system output: the BTM redefined. Natural systems "know" this and, given time, they tend to evolve into elaborate "ecologies" based on diversity rather than uniformity.

Our studies can be elaborated and refined to find more implications related to the shift from HEIA approaches to policies based on restricted access to resources. For example, the calculations can use more than one type of animal at the same time to study the effect of biodiversity in which a combination of low and high output subsystems is likely to better use variable resources (Coppock et al., 1986; Hofmann, 1989). This is done in practice by farmers who use left-over feeds for animals with lower output, e.g. idling or dry cows, bullocks or young animals. Also, the studies can be used to reassess the wisdom of allocating feed resources to either 'elite herds' that produce all milk, or to smallholders that produce the bulk in smaller quantities (Jackson, 1981). Further, they can analyse the benefits of reallocating (feed) resources over time through conservation or by using (animal) systems that "hibernate", i.e., that temporarily adjust to circumstances (Allden, 1970). It is interesting 
here to mention the point made by Columella in the first century A.D. (White, 1970): ... where fodder is scarce, cows should only be allowed to calve every second year, particularly when cows are used for farm work, to enable the cow to have an ample supply of nourishment for her calf and to save her the double burden of work and pregnancy... Last but not least, this type of scenario studies can elaborate the effect of indivisible production factors on optimum system size. In practice, the "partial" cow or production unit may have to be replaced with one or more small ones. Important in terms of equity (Conway, 1985), the (feed) resources for the "partial" unit can be either discarded, used for other purposes, or for a "partial" unit in another farming system.

In conclusion, changing resource/demand patterns require adjustment of present and design of new (farming) systems. In HEIA the restricted access to input is occasioned by public pressure to reduce waste. LEIA strategies provide phenomena that are masked in HEIA and our scenario studies indicate that under a given (feed) resource supply, the output targets of individual (animal) subsystems has to match the (feed) resource availability for maximum system output with minimum waste. Excessive targets for subsystem yield will negatively effect total system output, equity and waste disposal. In all cases, total system output (in terms of milk) increases with improved (feed) resource quality. This is achieved by reducing the number of (animal) subsystems, representing a trade-off between equity and total system output, i.e. use of better resources could lead to less farmers/producers for equal or higher system output. The damning objective related with a generalised form of "genotypeenvironment" interactions is at odds with a common interpretation of the BTM which tends to think that high input levels lead to better utilisation of all production factors and hence to minimum waste. Our results rather indicate the possibility to predict an ideal production target that matches the resource base for maximum system output. Segregation of (feed) resource pools, i.e., "selective consumption" allows increased total system output by accepting left-overs. We studied the LEIA approach in a strict sense but ultimately the design of sustainable systems has to strike a balance between the use of external resources in HEIA and the adjustment of subsystem output targets to resource conditions as in LEIA (Breman, 1994)

The models and cases are highly simplified representations of reality, but they are relevant for (HEIA) situations where problems of waste disposal require a reduction in the use of external inputs or else a better match of (animal) production units and (feed) resources. A single focus on (animal) subsystems with high individual outputs can aggravate problems of waste disposal in conditions of variable (feed) resource supplies. The focus on LEIA strategies brings to light aspects of system behaviour that do not come to the fore when allowing high external input use, i.e. phenomena such as genotype-environment interactions, the use of (bio)diversity, the damning objective and the communal ideotype. The results agree with thermodynamic and ecological theory. Further work could focus on issues of indivisibility (i.e. optimum size of production units), optimum herd composition (i.e. design of the total system) and the effect of refined maintenance requirements such as for pregnancy, milk consumed by calves (i.e. the effect of fixed costs). Another area of work is the application of these ideas to other sectors of society and scientific research. 


\section{Acknowledgements}

This paper reflects work with colleagues and students of the Animal Production Systems Group: A. Zurek, B.R. Patil, B.O. Brouwer, G. Zemmelink, N.W.M. Ogink, R. Pieterson, Yun Insiani, L. Kater and M. Bos. Thanks are due to A.W.M. Van Schie and E.A.M. Bokkers for assistance in preparing the final manuscript.

\section{References}

Aarts, H.F.M., Biewinga, E.E. and Keulen, H. van, 1992 Dairy farming systems based on efficient nutrient management. Netherlands Journal of Agricultural. Science 40: 285-299.

Alexander, G.I., G.K. Reason, G.M.R. Gale, \& C.H. Clark, 1984. The performance of Australian Friesian Sahiwal cattle. World Animal Review 52: 13-16.

Allden, W.G., 1970. The effect of nutritional deprivation on the subsequent productivity of sheep and cattle. Nutrition Abstracts and Reviews 40: 1167-1184.

Anonymous, 1987. Assisting livestock development, experience of development co-operation with reference to livestock in the period 1978-1984. Netherlands development co-operation, Directorate General of International Co-operation (DGIS), The Hague, $80 \mathrm{pp}$.

Anonymous, 1988. Nutrient requirements of dairy cattle, 6th Revised edition. National Academy Press, Washington DC, 157 pp.

Arthur, W.B., 1990. Positive feedbacks in the economy. Scientific American, Febr 1990: 80-85.

Barker, D.J. \& J.T. Stoate, 1969. Survival feeding of cattle during drought. Journal of Agriculture in western Australia 10: 34-39

Biewinga, E.E., H.F.M. Aarts \& R.A. Donker, 1992. Dairy farming under stringent environmental regulations (in Dutch). Report 98 -1992, Centre for Agriculture and Environment (CLM), Report 162 Centre for Agrobiological Research (CABO-DLO), Report 141 Experimental Station for Cattle Husbandry, Sheep Husbandry and Horse Husbandry (PR), 284 pp.

Breman, H. \& C.T. De Wit, 1983. Rangeland productivity and exploitation in the Sahel. Science 221: 1341-1347.

Breman, H., 1994. Sustainable agriculture in the Sahel? In: J. Bouma, A. Kuyvenhoven, B.A.M. Bouman, J.C. Luyten \& H.G. Zandstra, (Eds), Eco-regional approaches for sustainable land use and food production. Systems approaches for sustainable agricultural development. Volume 4, Kluwer Academic. Publishers, Dordrecht, pp. 213-235.

Cohen, J. \& I. Stewart, 1994. The collapse of chaos. Discovering simplicity in a complex world. Penguin Books, New York, 495 pp.

Conway, G.R., 1985. Agroecosystem analysis. Agricultural Administration 20: 31-55.

Conway, G.R., \& E.B. Barbier, 1990. After the green revolution, sustainable agriculture for development. Earthscan Publications Ltd., London, 205 pp.

Coppock, D.L., J.E. Ellis, \& D.M. Swift, 1986. Livestock feeding ecology and resource utilisation in a nomadic pastoral ecosystem. Journal of Applied Ecology 23: 573-583.

Daly, H.E., J.B. Cobb, \& C.W. Cobb, 1990. For the common good: redirecting the economy towards community, the environment and a sustainable future. Green Print, London, $482 \mathrm{pp}$.

De Boer, I.J.M., H.T.A. Peters, M. Grossman. \& W.J. Koops, 1997 Nutrient flows in agriculture in the Netherlands with special emphasis on pig production. Journal of Animal Science 75: 2054-2063.

De Haan, C., H. Steinfeld \& H. Blackburn, 1997. Livestock \& the environment finding a balance. WREN-media, Eye, Suffolk, UK, 115 pp.

De Wit, C.T., 1992. Resource use efficiency in agriculture. Agricultural Systems 40: 125-151.

De Wit, J., J.P. Dhaka, \& A. Subba Rao, 1993. Relevance of breeding and management for more or better straw in different farming systems. pp. 404-414. In: Kiran Singh \& J.B. Schiere, (Eds.), Feeding of ruminants on fibrous crop residues, Indian Council of Agricultural Research, New Delhi, Department of Animal Production Systems, Wageningen, $486 \mathrm{pp}$.

Donald, C.M., 1981. Competitive plants, communal plants, and yield in wheat crops. In: L.T. Evans \& 
W.J. Peacock (Eds.), Wheat science - today and tomorrow, Cambridge University Press, Cambridge, UK. pp 223-247.

Donald, C.M., 1962. In search of yield. Journal of the Australian Institute of agricultural Science 28: $171-178$.

Durning, A.B., \& H.B. Brough, 1991. Taking stock: animal farming and the environment. World Watch Paper 103, Washington. DC, USA.

Farrington, T., D.K.V. Marsh, \& L. Mayer, 1989. Winter fattening of beef cattle: from research station trials to implementation by farmers. Agricultural Systems 29: 165-178.

Fraser, A., 1949. Sheep husbandry, Crosby Lockwood \& Son Ltd, London, 297 pp.

Frisch, J.E. \& J.E. Vercoe, 1978. Utilising breed differences in growth of cattle in the tropics. World Animal Review 25: 8-12.

Hayman, R.H., 1974. The development of the Australian milking zebu. World Animal Review 11: 31-35.

Hofmann, R.R., 1989. Evolutionary steps of ecophysiological adaptation and diversification of ruminants: a comparative view of their digestive system. Oecologia 78: 443-457.

Ifar, S., 1996. Relevance of ruminants in upland mixed-farming systems in East Java, Indonesia. PhD thesis, Wageningen Agricultural University, Wageningen. 139 pp.

Jackson, M.G., 1981. A new livestock development strategy for India. World Animal Review 37: 2-8.

Jones, R.J. \& R.L. Sandland, 1974. The relation between animal gain and stocking rate, derivation of the relation from the results of grazing trials. Journal of Agricultural Science (Cambridge) 83: 335-342.

Kamalzadeh, A., 1996. Prospects of compensatory growth for sheep production systems. PhD thesis, Wageningen Agricultural University, Wageningen, $211 \mathrm{pp}$.

Kelley, J., 1992. Upgrading of waste cereal straws. Outlook on Agriculture 21: 105-108.

Ketelaars, J.J.M.H. \& B.J. Tolkamp, 1992. Towards a new theory of feed intake regulation in ruminants. 1. Causes of differences in voluntary feed intake: critique of current views. Livestock Production Science 30: 269-296.

Kidane, H., 1984. The economics of farming systems in the different ecological zones of Embu District (Kenya), with special reference to dairy production. PhD thesis, Hannover University, Hannover, 227 pp.

Kingwell, R.S. \& D.J. Pannell (Eds.), 1987. MIDAS - a bioeconomic model of a dryland farm system. Simulation Monographs, Pudoc, Wageningen, $207 \mathrm{pp}$.

Morrison, F.B., 1961. Feeds and feeding. The Morrison Publishing Company, Claremont, Ontario, Canada, 696 p.

Morrison, D.A., R.S. Kingwell, D.J. Pannell, \& M.A. Ewing, 1986. A mathematical programming model of a crop-livestock farm system. Agricultural Systems 20: 243-268.

O’Donovan, P.B., 1984. Compensatory gain in cattle and sheep. Nutrition Abstracts Reviews Series B 54: 389-410.

Odum, H.T., 1971. Environment, power and society. Wiley Interscience, New York, 331 pp.

Patil, B.R., D.V. Rangnekar, \& J.B. Schiere, 1993. Modelling of crop-livestock integration: effect of choice of animals on cropping pattern. In: Kiran Singh \& J.B. Schiere (Eds.), Feeding of ruminants on fibrous crop residues. Indian Council for Agricultural Research (ICAR), New Delhi, pp. 336-343.

Prigogine I., \& I Stengers, 1984. Order out of chaos, man's new dialogue with nature. Flamingo, London, $349 \mathrm{pp}$.

Rerat, A. \& S.J. Kaushik, 1995. Nutrition, animal production and the environment, Water Science Technology 31: 1-19.

Romero C. \& T. Rehman, 1989. Multiple criteria analysis for agricultural decisions. Developments in agricultural economics 5, Elsevier, Amsterdam, 257 pp.

Schiere, J.B., 1995. Cattle, straw and system control; a study of straw feeding systems. PhD thesis, Wageningen Agricultural University, Wageningen, 216 pp.

Schiere, J.B. \& J. De Wit, 1993. Feeding standards and feeding systems. Animal Feed Science and Technology 43: 121-134.

Schiere, J.B, J. Lyklema, J. Schakel and K. Rickert, 1999, Evolution of farming systems and system philosophy. Journal of Systems Research and Behavioral Science 16: 375-390.

Sol, J., J.A. Renkema, \& A. Brand, 1984. A three year herd health and management program on thirty Dutch dairy farms. IV. Special aspects. The Veterinary Quarterly 6: 163-169. 
Staniforth, A.R., 1982. Straw for fuel, feed and fertiliser. Farming Press Ltd., Ipswich, 153 pp.

Stoorvogel, J.J., R.A. Schipper \& D.M. Jansen, 1995. USTED: a methodology for quantitative analysis of land use scenarios. Netherlands Journal of Agricultural Science 43:5-18

Udo, H.M.J. \& B.O. Brouwer, 1993. A computerised method for systematically analysing the livestock component of farming systems. Computers and Electronics in Agriculture 9: 335-356.

Van De Ven, G.W.J., 1996. A mathematical approach to comparing environmental and economic goals in dairy farming on sandy soils in The Netherlands. Ph.D. thesis. Wageningen Agricultural University, Wageningen, $239 \mathrm{pp}$.

Van Der Meer, H.G., R.J. Unwin, T.A. Van Dijk \& G.C. Ennik, (Eds), 1987. Animal manure on grassland and fodder crops. Fertilizer or waste? Martinus Nijhoff Publishers, Dordrecht / Boston / Lancashire, $388 \mathrm{pp}$.

Van Der Pol, F., 1992. Soil mining: an unseen contributor to farm income in southern Mali. Bulletin 325, Royal Tropical Institute (KIT), Amsterdam, 48 pp.

Van Niejenhuis, J.H. \& J.A. Renkema, 1989. The construction of models for the mathematical programming of agrarian enterprises (In Dutch). Wageningen Economic Studies 15, Pudoc, Wageningen, 171 pp.

Veldkamp A. \& L.O. Fresco, 1996. CLUE-CR: an integrated multi-scale model to simulate land use change scenarios in Costa Rica. Ecological Modeling 91: 231-248.

Wahed, R.A., E. Owen, M. Naate \& B.J. Hosking, 1990. Feeding straw to small ruminants. Effect of amount offered on intake and selection of barley straw by goats and sheep. Animal Production 51: 283-289.

White, K.D., 1970. Roman farming. Thames \& Hudson, London, 536 pp.

Zemmelink, G., 1980. Effect of selective consumption on voluntary intake and digestibility of tropical forages. Agricultural Research Report 896, Pudoc, Wageningen, 100 pp.

Zemmelink G., 1986. Measuring intake of tropical forages. In: C.C. Balch \& A.J.H. Van Es (Eds), Recent advances in feed evaluation and rationing for dairy cattle in extensive and intensive production systems. Bulletin No.196. International Dairy Federation, Brussels, pp.17-21.

Zemmelink, G., B.O. Brouwer, \& S. Ifar, 1992. Feed utilisation and the role of ruminants in farming systems. In: M.N.M. Ibrahim, R. De Jong, J. Van Bruchem, \& H. Purnomo, (Eds.), Livestock and feed development in the tropics. Brawijaya University, Malang, pp. 444-451. 